\title{
AC 2008-699: MICROELECTRONIC ENGINEERING AND NANOTECHNOLOGY EDUCATION FOR UNDERGRADUATES AND PRE-COLLEGE STUDENTS THROUGH CURRICULUM REFORM AND OUTREACH ACTIVITIES
}

\section{Santosh Kurinec, Rochester Institute of Technology}

Santosh K. Kurinec is Professor and the Department Head of Microelectronic Engineering at Rochester Institute of Technology. She has led the effort on curriculum reform and is the Principle Investigator of this work. She teaches courses on microelectronic processing and electronic materials. She has extensive experience on materials integration in semiconductor devices.

\section{Michael Jackson, Rochester Institute of Technology}

Mike Jackson is an Associate Professor of Microelectronic Engineering at Rochester Institute of Technology. His research experience includes materials, thin films and metrology. He directs outreach activities in the Department of Microelectronic Engineering at RIT.

\section{Thomas Schulte, Rochester Institute of Technology}

Tom Schulte is a science teacher at the West Irondequoit High School, Rochester, NY. He is the K-12 Outreach Coordinator for the Department of Microelectronic Engineering at Rochester Institute Technology. He brings a unique combination of engineering education, industrial experience and high school teaching.

\section{Nathaniel Kane, Rochester Institute of Technology}

Nate is an undergraduate student of BS program in Microelectronic Engineering. Nate has served this work in being the first service learning intern in a local high school.

\section{Elaine Lewis, Rochester Institute of Technology}

Elaine Lewis is the Outreach Specialist in the Department of Microelectronic Engineering at RIT. Elaine served as photolithography engineer at General Electric and Eastman Kodak Company prior to joining RIT. She is dedicated to communicating science and engineering to K-12 teachers and students.

\section{Surendra Gupta, Rochester Institute of Technology}

"Vinnie" Gupta is a Professor of Mechanical Engineering and Materials Science \& Engineering, and the recipient of the 2000 Eisenhart Award for Excellence in Teaching. At RIT, he teaches undergraduate and graduate courses in Applied Mechanics, Computational Techniques, and Materials Science. 


\title{
Microelectronic Engineering and Nanotechnology Education for Undergraduates and Pre-College Students through Curriculum Reform and Outreach Activities
}

\begin{abstract}
The extension of microelectronics to new frontiers that include MEMS, nanotechnology, flexible electronics, biotechnology, energy and solid state lighting is inevitable. Development of a necessary multi faceted work force is critical to our nation's innovation edge in these fields. The Department of Microelectronic Engineering at Rochester Institute of Technology received an NSF implementation grant in 2005 to institute a major department level reform (DLR) to address this critical need. The key elements of this effort consist of curriculum reform in the main program, creation of a novel minor program and diverse activities to reach out to K-12 and precollege community. The curriculum reform consisting of creation of free electives through course consolidations and new course development that included a new nanocharacterization laboratory based course has been instituted. A K-12 teachers' forum on microelectronics and nanotechnology has been developed and delivered. A program package that includes instructional materials, available for wider dissemination, has been developed. A unique 'service learning' co-op experience has been piloted where an engineering student spent two academic quarters in a high school under the guidance of the physics teacher to develop physics laboratories and mentor students in math and science. Feedback from students outlined the benefit of having another knowledgeable individual in the classroom to gain insight about careers in engineering which hopefully will translate into students choosing engineering as a career. These initiatives have significantly enhanced the educational programs at RIT.
\end{abstract}

\section{Introduction}

The semiconductor industry has entered nanotechnology. The smallest feature size printed on an integrated circuit is known as the technology node. The industry has already announced its readiness for the $45 \mathrm{~nm}$ technology node in production with $32 \mathrm{~nm}$ node on the horizon. The curricula developed by Rochester Institute of Technology (RIT) have kept pace with the rapid advancements sharing 25 of the 40 years of the Moore's Law and have contributed significantly in generating the workforce and research for this growing high tech industry. One of the great challenges for the future microelectronics and semiconductor technology will be the need to draw on scientific principles and engineering developments from such an extraordinary wide range of disciplines not adequately provided by traditional engineering or science programs. Education must not only keep pace with this trend but also lead and foster this growth. The opportunities in nanoelectronics are considerable. It is predicted that CMOS will be supplemented by novel nano-enabled solutions. Prudent semiconductor manufacturers must plan for nanotech's impact on their businesses today and prudent educators must plan for educating a high tech engineering workforce.

The Bachelor of Science program in Microelectronic Engineering at RIT started in 1982 with basic PMOS process on 2" wafers. Today, the program supports a complete 4 and 6 inch CMOS line equipped with diffusion, ion implantation, plasma PVD and CVD processes, electro- 
deposition, chemical mechanical planarization, I-line and deep UV wafer steppers, Perkin Elmer MEBES III electron beam mask writer, and device design, modeling and test laboratories. The program remains the only ABET (Accreditation Board for Engineering and Technology) accredited Bachelor of Science program granting a degree in Microelectronic Engineering. The program, which includes 5 quarters of required co-op, currently has over 130 undergraduate students. The co-op program commences after the second year, and students alternate school with paid employment in the semiconductor industry. The laboratories at RIT include the largest university clean room for IC fabrication and are partially supported by our industrial affiliates, who provide curriculum input and support through donations of equipment. ${ }^{1,2}$

\section{Reformulation of the BS Program in Microelectronic Engineering $(\mu \mathrm{E})$}

A major institute wide initiative was undertaken and completed in the year 2005. This reform required restructuring the BS program in all engineering and science programs at RIT to create 'five electives' in each program to enable students take courses in other disciplines.

The new curriculum has 196 quarter credits that include 12 credits of free electives, 8 credits of professional electives, 92 credits of general education and five quarters of co-op experience. The combination of 3 free and 2 professional electives allows students to take a five-course minor. Students have found this extremely attractive as a larger number of students are enrolling in various minors across a wide range of disciplines. ${ }^{3}$

Implementation of this program required updating some courses/laboratories and elimination of legacy material and course consolidation. The enhancements implemented include development of e-beam lithography and nanoscope capability. Scanning probe microscopes (SPMs) are a class of tools that enable the nanoscale world to be imaged, measured, and manipulated. We have set up a new atomic force microscope laboratory that performs all major SPM techniques including electric force microscopy, scanning tunneling microscopy, scanning thermal microscopy, and scanning capacitance microscopy. A new course "Nanocharacterization" has been developed. ${ }^{4}$

\section{Minor in Microelectronics and Nanofabrication for Non- $\mu$ E Students}

We have developed a five course minor in microelectronics for non- $\mu \mathrm{E}$ science and engineering students who desire exposure and experience to the exciting world of nanotechnology. We believe that this minor may do more to increase the number of women students with engineering experience at RIT by utilizing the large number already enrolled in the College of Science programs, as opposed to separate recruitment strategies geared solely toward engineering. This program is designed to provide basic knowledge to students from other engineering and science disciplines interested in a career in the semiconductor industry that include design, manufacture, equipment, chemicals, and software sectors. The minor consists of five courses: three core and two electives as given in Table I. The prerequisites for each of these courses are basic university level math, physics and one course in chemistry. The courses are multidisciplinary in content so there is an enormous knowledge value for students of every science/engineering program. These five courses will equip students from other disciplines to work in the semiconductor industry or go to graduate programs in emerging fields of MEMS, nanotechnology. For instance, electrical engineering students with fabrication and processing knowledge will be better circuit designers 
and understand the tools and relationships between electrical data and process conditions. Computer engineers will be better chip designers. Mechanical engineers, largely employed by the equipment industry and packaging industry will be at an advantage by knowing the processes involved. Similarly, chemistry students will find better job opportunities with chemical industries that support semiconductor fabs. The industrial engineers will be exposed to the fab layout, wafer flow, lot tracking and other manufacturing issues. Physics/materials science majors will be the top choice for operating and interpreting electron microscopy, surface analysis, Raman and other spectroscopic techniques.

\begin{tabular}{|l|l|}
\hline \multicolumn{2}{|l|}{ TABLE I: Microelectronics and Nanofabrication Minor Curriculum } \\
\hline Level & Courses \\
\hline Freshmen Level & Introduction to Micro/NanoLithography \\
\hline Sophomore Level & IC Technology \\
\hline Senior Level & Thin Film Processes \\
\hline \multirow{5}{*}{ Two Electives } & Nanocharacterization \\
\cline { 2 - 2 } & CMOS Processing Lab \\
\cline { 2 - 2 } & Process and Device Modeling \\
\cline { 2 - 2 } & Nanoscale CMOS and Beyond \\
\cline { 2 - 2 } & Other Discipline Specific Nano Courses \\
\hline
\end{tabular}

\section{Concentration in Nanotechnology}

A long-term perspective suggests a tighter linkage between electronics technology and molecular biology. Our focus is on integration of nanotechnology with electronics - the 'beaker to chip' approach. We aim at preparing students who can integrate chemical, biological and other types of materials with on-chip circuitry. Table II lists the proposed curriculum for this concentration.

\begin{tabular}{|l|l|}
\hline \multicolumn{2}{|c|}{ TABLE II: Nanotechnology Concentration } \\
\hline Required Courses & Status \\
\hline Introduction to Nanotechnology & To be offered in Fall/Winter 2007 \\
\hline Nanofabrication & To be offered in Winter/Spring 2007 \\
\hline Quantum and Nanostructures Physics & Modified for Fall 2007 offering \\
\hline Elective Courses & \\
\hline Nanocharacterization of Materials Surfaces & Currently offered in Spring \\
\hline Nanoscale CMOS and Beyond & Currently offered in Winter \\
\hline Additional relevant courses from other programs & \\
\hline
\end{tabular}

These courses are multidisciplinary and taught by faculty from different disciplines. In addition to these 'core' courses, we will consolidate nanotechnology related courses currently being taught either as 'special topics' or as 'pilot' programs. Inclusion of nano courses from biology, electrical engineering, mechanical engineering, physics and chemistry will also be available as electives. This way, students could customize their nanotechnology concentration. 


\section{Outreach Activities}

The evolution of our engineering curriculum should be communicated to high school teachers and guidance counselors so that they are better informed as to the future trends and needs of industry, and can disseminate that information to their students thereby encouraging increased enrollments in sciences and engineering. A K-12 Outreach forum on Microelectronics and Nanotechnology has been developed and delivered. The contents of this forum are given in Table III. ${ }^{5}$

\begin{tabular}{|l|}
\hline \multicolumn{1}{|c|}{ Table III: 2-Day K-12 Teachers Forum at RIT } \\
\hline Session I \\
\hline Origin of nanoelectronics and the promise of nanotechnology \\
\hline Fundamentals of semiconductor devices \\
\hline Electronics laboratory experience: electrical measurements on basic devices \\
\hline Materials science of nanofabrication: Overview of unit integrated circuit fabrication processes \\
\hline Microscopy and lithography lab experience \\
\hline Session II \\
\hline Snapshot of today's high technology fields \\
\hline Emerging technologies (Technology roadmap, MEMs, nanotechnology) \\
\hline $\begin{array}{l}\text { Forum for high school teachers: where and how could, today's high school curriculum prepare } \\
\text { students for these hi-tech careers? }\end{array}$ \\
\hline Academic programs and research, discussion with undergraduate and graduate students. \\
\hline Forum between faculty and teachers; opportunities, gaps, challenges, actions \\
\hline
\end{tabular}

Figure 1 shows K-12 course attendees conducting photolithography in a cleanroom and assembling an electronic circuit.

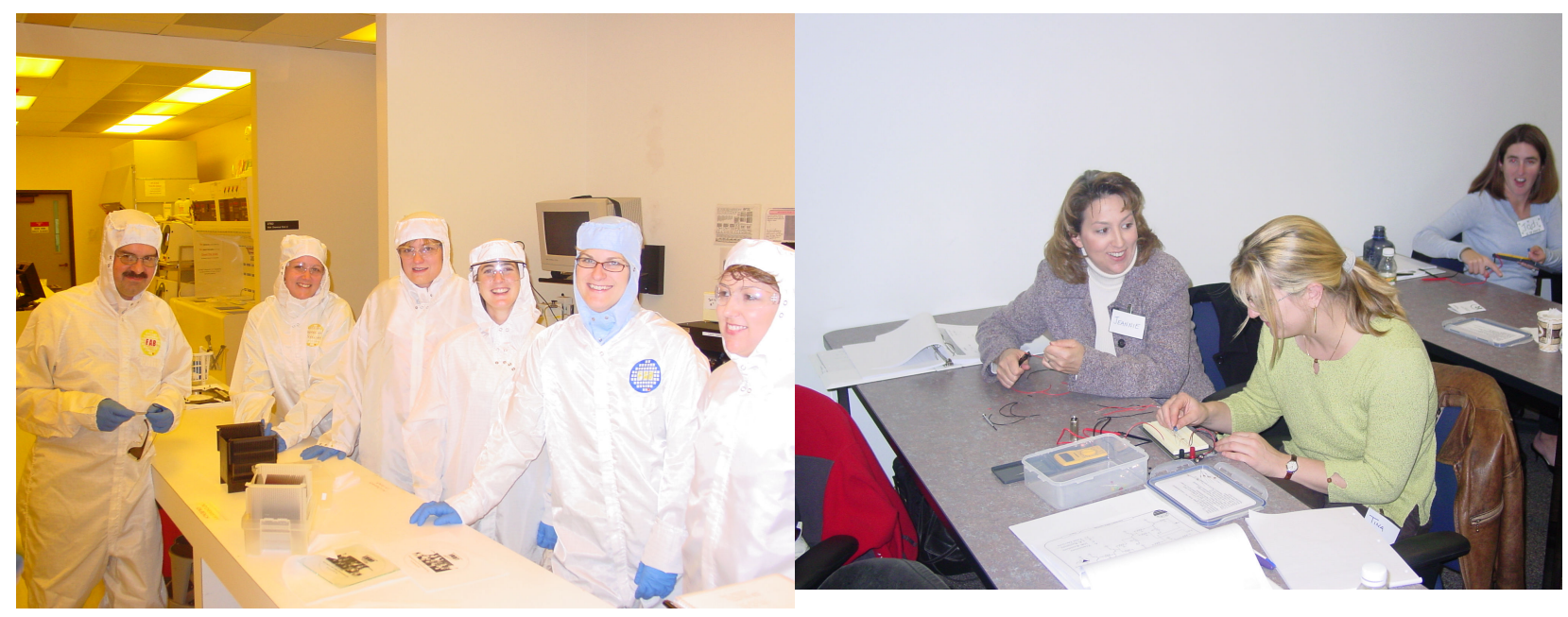

Fig.1. K-12 Forum on Microelectronics and Nanotechnology participants conducting laboratory in the RIT microelectronics cleanroom (left); Participants trying electronic device test kit prepared by RIT faculty (right). 
Upon completion of the K-12 Forum on Microelectronics and Nanotechnology, an assessment was performed through a questionnaire survey in addition to general deliberation. In the survey, the quality of each session was rated and comments were invited. The rating was performed using a Likert Scale in which a value of 5 represented very satisfied and a value of 1 represented not satisfied. Figure 2 represents the average rating given to each presentation.

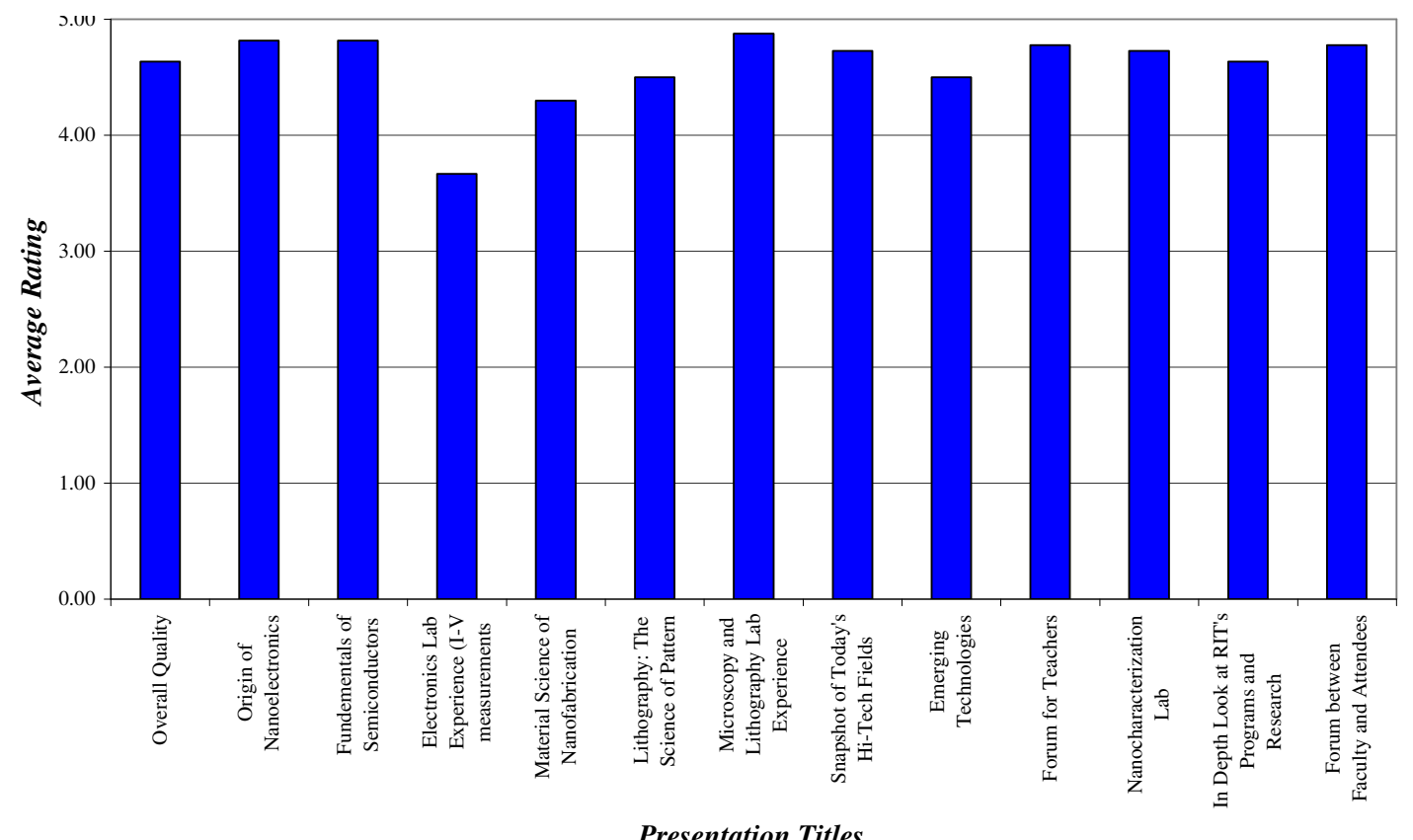

Fig. 2. Results of K-12 forum attendees' response to survey questionnaire.

The above results show that the forum was very successful on an immediate short term assessment. In long term, we will be assessing its impact. We are working on further improving the content and delivery and reach out wider area schools. The discussions at the forum also revealed a critical need for involving high school guidance personnel in future forums.

\section{Service Learning}

Service-Learning (SL) is an educational method and practice of teaching by which participants learn and develop through active participation in services that meet the needs of the community. ${ }^{6}$ An extensive study was carried out on the Service Learning (SL) initiatives at various universities. To implement SL one may utilize an array of methods specific to the discipline involved - the key is identifying need and creating a program with solid communication between its constituents. SL and microelectronic engineering is difficult, but not impossible. For example, mechanical and electrical engineering is much more dynamic from a community needto-product standpoint than microelectronic engineering. The products of mechanical and electrical engineers are tangible - you can build something great in a garage. This is quite the opposite when considering microelectronic engineering, a topic that is seldom known to the outside observer. Unlike other disciplines, however microelectronic engineers are in a unique position to make an impact on the High School and Junior High School levels where the iPods, cell phones, PDAs, and hand-held cameras rein supreme. Microelectronic engineers are capable 
of bringing a wealth of information, knowledge, and understanding of topics appealing to the potential biologists, chemists, mathematicians, and physicists.

A novel service learning co-op program has been piloted - placing an engineering undergraduate student in a high school. Nate Kane, from the Microelectronic Engineering Department at RIT was hired to work in the Regents and AP Physics classroom of Tom Schulte, Science teacher at West Irondequoit High School. At the onset of the experience, the major goal was the assistance in modifying or creating laboratory experiences that engaged the students in inquiry based activities. It was expected that through this work, students would be engaged in higher levels of critical thinking, and learn to work efficiently and effectively in a group setting to solve a common problem.

The results of this work produced two major milestones. First, a lab was created that exposed students to the law and conservation of energy, and the principle of simple harmonic motion. Students were required to identify variables that might affect the period of an oscillating pendulum and through graphical analysis determine the general empirical expression for the period of an oscillating pendulum and spring. The second major milestone was the development, coordination, and implementation of a cardboard boat race that included AP students from West Irondequoit High School and Batavia High School. This was the culminating project for students who had challenged the AP-B Physics course. Student teams were tasked with designing a boat made solely from cardboard and duct tape that would carry two students across a school swimming pool. Understanding concepts in structural design and buoyancy were critical to this project. It provided faster response to student questions and certainly made for a stronger learning environment in teacher's classroom. The response to this program during the first quarter was positive from both a student perspective as well as a teacher perspective. The ability to have someone with the necessary technical knowledge to help strengthen the lab component of a course is invaluable especially when time is very limited for individually work on. The access to a second person in the classroom to assist students working in small groups provides faster response time to student questions as well as provides multiple approaches to problem solving which helps student learning.

These have been piloted efforts and sustaining these will require substantial support from the institution and industry.

\section{Conclusions}

The rapid advancements in the semiconductor industry have brought the technology into new realms of nanotechnology and micro/nano systems engineering. With the support provided by the National Science Foundation and RIT Provost's vision, a major curricular restructuring has been made possible in Microelectronic Engineering programs at RIT. The efforts have been successful in creating modern and novel curricula, outreach and service learning opportunities. These initiatives are extremely critical in producing the next generation of engineers to stay ahead in innovations and be globally competitive. However, the authors believe that it will require continued concerted efforts between university and K-12 educators, administrators, leaders and the community. 


\section{Acknowledgements}

The authors acknowledge the support provided by the National Science Foundation through the grant number EEC- 530575. This paper was presented at the ASEE St. Lawrence Section Meeting held in Toronto, ON in October 2007.

\section{Bibliography}

1. 25 Years of Microelectronic Engineering Education, Santosh Kurinec, Lynn Fuller, Bruce Smith, Richard Lane, Karl Hirschman, Michael Jackson, Robert Pearson, Dale Ewbank, Sean Rommel, Sara Widlund, Joan Tierney, Maria Wiegand, Maureen Arquette, Charles Gruener and Scott Blondell, 16th Biennial University Government Industry Microelectronics Symposium, San Jose State University, San Jose, CA, June 2006, p.23

2. Online Master of Engineering Program in Microelectronics Manufacturing Engineering: A Valuable Resource for Engineers in Semiconductor Industry", Santosh Kurinec, Dale Ewbank, Daniel Fullerton, Karl Hirschman, Michael Jackson, Robert Pearson, Sean Rommel, Bruce Smith and Lynn Fuller, Joeann Humbert, Leah Perlman, Ian Webber, " 9 th International Conference on Engineering Education, San Juan, Puerto Rico, July 2006, TIA1-5.

3. Microelectronic Engineering Education for Emerging Frontiers, Santosh Kurinec, Dale Ewbank, Lynn Fuller, Karl Hirschman, Michael Jackson, Robert Pearson, Sean Rommel Bruce Smith and Surendra Gupta Maureen Arquette and Maria Wiegand, $9^{\text {th }}$ International Conference on Engineering Education, San Juan, Puerto Rico, July 2006, TIA1-5.

4. Micro- and Nano- Characterization of Materials, Surendra K. Gupta, Proceedings of the $9^{\text {th }}$ International Conference on Engineering Education, San Juan, PR, July 2006.

5. Curriculum Innovations in Microelectronic Engineering, Santosh K. Kurinec, Surendra K. Gupta, Raymond Krom, Thomas Schulte and Michael A. Jackson, Interdisciplinary Innovation and Imagination in Engineering Education $\left(I^{3} E^{2}\right)$ - American Society for Engineering Education, St. Lawrence Section Conference, Cornell University, November 17-18, 2006.

6. Service learning: Engineering in your community, Lima, M. and Oakes, W. (2005), Great Lakes Press. 